\title{
Filtering parenteral nutrition
}

\author{
S. Harwood, S. Huey, A. Jukes, W. Magambo, S. Tracey and A. B. Hawthorne \\ University Hospital of Wales, Heath Park, Cardiff CF14 4XW
}

Current evidence advocates filtering parenteral nutrition $(\mathrm{PN})$ in patients who require prolonged parenteral therapy and the immunocompromised $^{(1)}$. Almost all adult patients receiving parenteral nutrition at University Hospital Wales, Cardiff fall into either or both of these categories.

In November 2007, a pilot study was carried out to investigate the possibility of adding giving sets and filters to PN infusion bags in pharmacy aseptic services (AS). The Pall TNA 2E 1.2 micron filters were used for all infusions. Although there were some minor problems, the study concluded this was a feasible option.

In January 2008, the addition of giving sets and filters to adult PN infusion bags in pharmacy AS was made permanent. Three months after initiating the change, an audit revealed overall satisfaction was good. Minor problems were reported, namely, the weight of the filters on patients central lines and the packing of the PN in protect from light covers. One year later an audit revealed an overall satisfaction with amended practice as, again, good. Problems reported included a small number of nursing staff having difficulties priming the filter and the weight of the filter on the central and peripheral lines.

Line infection data have been compared pre- and post-adding giving sets and filters in AS:

\begin{tabular}{|c|c|c|c|c|}
\hline & \multicolumn{2}{|c|}{ February 2007-January 2008} & \multicolumn{2}{|c|}{ February 2008-January 2009} \\
\hline & Number of lines & $\%$ & Number of lines & $\%$ \\
\hline No infection & 89 & 76.7 & 67 & 81.7 \\
\hline Proven infection & 18 & 15.5 & 11 & 13.4 \\
\hline Possible infection & 4 & 3.4 & 3 & 3.7 \\
\hline Tunnel/exit site infection & 2 & 1.7 & 1 & 1.2 \\
\hline Failed insertion & 1 & 0.9 & 0 & 0 \\
\hline Mechanical complication & 1 & 0.9 & 0 & 0 \\
\hline Data inconclusive & 1 & 0.9 & 0 & 0 \\
\hline Total & 116 & 100 & 82 & 100 \\
\hline
\end{tabular}

The data show that adding given sets and filters to PN infusions in pharmacy AS has not increased the number of infected lines. In fact the number of infected lines has decreased and the number of infection free lines has increased since the implementation of this change.

1. Bethune K, Allwood M, Granger C et al. (2001) Nutrition 17, 403-408. 